\title{
BRAND SWITCHING SMARTHPHONE (XIOMI DAN OPPO) PADA ERAFONE MEGASTORE DI KOTA DENPASAR
}

\author{
Desak Made Febri Purnama Sari, Dewa Ayu Pt Yusirika Tirani Dewi \\ Fakultas Ekonomi dan Bisnis Universitas Pendidikan Nasional (Undiknas), Bali, Indonesia \\ dskfebripurnama@undiknas.ac.id
}

\begin{abstract}
ABSTRAK
Brand Switching Smarthphone (XIOMI dan Oppo) pada Erafone Megastore di Kota Denpasar. Penelitian ini bertujuan untuk mengetahui pengaruh promotion, personal selling, dan price terhadap brand switching smarthphone (xiomi dan oppo) pada erafone megastore di kota denpasar. Populasi penelitian ini konsumen yang berkunjung pada Erafone Megastore di Kota Denpasar, dengan sampel 80 responden. Pengumpulan data menggunakan kuesioner dengan alat ukur skala likert. Jenis data yang digunakan pada penelitian ini adalah data data kuantitatif. Metode analisis data yang digunakan pada penelitian ini menggunakan analisis uji validitas, uji reliabilitas, uji asumsi klasik, dan uji analisis regresi linier berganda dengan menggunakan aplikasi SPSS version 22.0. Hasil penelitian ini menyatakan promotion, personal selling, dan price berpengaruh positif dan signifikan secara parsial dan simultan terhadap brand switching smarthphone (xiomi dan oppo). Hal ini berarti 59,9\% variasi variable brand switching dapat dijelaskan oleh variasi dari ketiga variable independent promotion,personal selling dan price. sedangkan sisanya $(100 \%-59,9 \%=40,1 \%)$ dijelaskan oleh sebab-sebab lain diluar model yaitu seperti variable citra merek, pelayanan, dan kualitas produk.
\end{abstract}

\section{Kata Kunci: Promotion, Personal Selling, Price Dan Brand Switching}

\section{LATAR BELAKANG}

Perangkat telekomunikasi elektroik yang memiliiki kemampuan dasar yang sama dengan kemampuan telepon konvensional saluran tetap, namun dapat dbawa ke manamana dan tidak perlu disambungkan dengan jaringan telepon menggunakan kabel. Seiring perkembangan zaman, ponsel telah menjadi kebutuhan primer, bukan saja untuk pebisnis namun hampir seluruh kalangan memerlukan ponsel guna kepentiingannya masing-masng. Perusahaan smartphone sendiri tentunya memiliki keunggulan masing-masing untuk dapat bersaing dengan perusahaan lain dan semuanya bersaiiing dalam merebutkan pasar konsumen melalui barbagaii macam terobosan dan inovasi yang telah mereka ciptakan. Di Indonesiia sendiri terdapat beberapa merek smartphone yang bersaing dalam merebutkan pasar konsumen antara lain: Samsung, Apple, Nokia, Sony, Xiaomi, Oppoo, Lenoo, Asuss dan lain-lain.

Peter dan Olson (2015) sedangkan Mowen (2013)mengartikan perilaku Brand Switching sebagai kebaliikan dari keinginan perilaku pembelian ulang sebagai implikasi kepuasan. Dalam era kemajuan teknologi saat ini konsumen tentunya dalam melakukan pembelian juga mempertimbangkan faktor yang mempengaruhii brand switching. Asr (2014) menyatakban bahwa promotion adalah segala usaha yang dilakukan penjual untuk memperkenalkan produk kepada calon konsumen dan membujuk mereka agar membeli, mengingatkan kembali konsumen lama agar melakukan pembelian ulang. Promotion merupakan sarana yang digunakan oleh orang-orang untuk berinteraksi satu sama lain dengan cara menciptakan, berbagi serta bertukar informasi dan gagasan dalam sebuah jaringan dan komuntas. 
Personal selling juga merupakan promoton yang dilakukan melalui pribadi- pribadi karyawan dalam melayani serta ikut mempengaruhi nasabah (Simamora,

2013). Dengan kemampuan personal selling yang baik belum dapat memaksimalkan terjadinya brand switching. Hal ini disebabkan konsumen sudah mulai memperhatikan perbandingan harga dari smartphone xiomi dan smartphone oppo yang merupakan faktor terjadinya perpindahan merek. Nanda (2018) yang mengatakan kondisi ini menunjukkan bahwa para harga yang menarik dan di imbangi dengan kualitas berdampak positif terhadap brand switcing, begitu juga sebaiknya dimana harga yang tinggi dan tidak dimbangi dengan kualitas merek smartphone yang baik berdampak negativ terhadap brand switchng smartphone. Menurut Ki rana (2017), beberapa hal yang mempengaruhi adanya brand switchiing pada smartphone diiantaranya adalah kurangnya menariknya promosi yang dilakukan dalam penjulan smartphone berdampak pada terjadinya brand

switchng, serta kurangnya pengetahuan produk dari sales dalam memasarkan produk smartphone berdampak pada keinginan konsumen melakukan perpindahan pembelian smarthphone. (Manajemen, Made, \& Purnama, 2018) dengan adanya brand image yang melekat diproduk xiomi dan oppo yang membuat produk menjadi mudah diingat menyebabkan perputaran merek dari Xiomi ke Oppo karena brand image adalah kemajuan tekonologi yang sangat pesat terutama smarthphone. Price juga berdampak dalam mepengaruhi konsumen dalam pembelian smartphone diimana price yang mahal dan tidak dimbangi dengan kualitas smartphone berpengaruh terhadap terjadinya brand switching. Brand Switching adalah pola pembeliian yang dikarakteritikan dengan perubahan atau pergantian dari satu merek ke merek yang lain (Peterr dan Olsonn, 2015) Sedangkan Mowen (2013), mengartikan perilaku Brand Switching sebagai kebalikan dari keinginan perilaku pembelian ulang sebagai implikasi kepuasan.

\section{Perumusan Masalah}

Bagaimanakah pengaruh Promotion, Personal Selling dan Price terhadap Brand

Switching Smartphone (Xiaomi dan Oppo) pada Erafone Megastore di Kota Denpasar?

\section{Tujuan Penelitian}

Untuk mengetahui pengaruh Promotion, Personal Selling dan Price terhadap Brand Switching Smartphone (Xiaomi dan Oppo) pada Erafone Megastore di Kota Denpasar.

\section{Promotion}

\section{KERANGKA TEORITIS}

Promotion adalah semua kegiatan yang dimaksudkan untuk menyampaikan atau mengkomuniikasiikan suatu produk kepada pasar sasaran, untuk memberii informasi tentang keistimewaan, kegunaan dan yang paling penting adalah tentang keberadaannya, untuk mengubah siikap ataupun untuk mendorong orang untuk bertindak dalam membeli suatu produk (Subagyoo, 2014). Menurutt Kottler dan Kellerr (2014), promotion penjualan adalah salah satu unsur dalam kampanye pemasaran yaitu berbagai kumpulan alat-alat insentif yang sebagain besar berjangka pendek, yang dirancang untuk merangsang pembelian produk atau jasa tertentu dengan lebih cepat dan lebih besar oleh konsumen atau pedagang.

S

\section{Personal Selling}

Personal selling merupakan bagian dari kegiatan promotion yaitu cara untuk memperkenalkan dan menarik minat konsumen yang di tawarkan secara tatap muka. Komunikasi yang dilakukan kedua belah pihak bersifat interaktif atau komunikasi dua arah sehingga penjual dapat langsung memperoleh tanggapan sebagai umpan baliik tentang keinginan dan pendapat konsumen. Penyampaian atau proses komunikasi dapat dilakukan dengan sangat fleksibel karena dapat disesuaikan dengan situasi yang ada (Kotlerr \& Kellerr, 2013). 


\section{Price}

Price adalah sejumlah nilai yang ditukarkan calon konsumen dengan manfaat dari memiliki atau menggunakan produk atau jasa yang nilainya ditetapkan oleh pembeli dan penjual melaluii tawar-menawar, atau ditetapkann olehh penjuall untuk satu price yang sama terhadapp semuaa pembeli. Adapun faktorr yang harus diperhatikan dalam suatu penetapan price yaitu biaya, keuntungan, price yang ditetapkan oleh pesaing dan perubahan keinginan pasar. Secara umum, penetapan price bertujuan untuk memperbesar market share dan mencari laba agar perusahaan dapat berjalann (Swasthaa \& lirawan,2013).

\section{Brand Switching}

Menurut Peter dan Olson (2015), brand switching adalah pola pembelian yang dikarakteristikan dengan perubahan atauu pergantian dari satu merek ke merek yang lain. Sedangkan Mowen (2013), mengartikan perilaku Brand Switching sebagai kebalikan dari keinginan perilaku pembeliian ulang sebagai implikasi kepuasann. Menurut Spacey(2017), brand switching adalah saat dimana seorang pelanggan atau sekelompok pelanggan berpindah kesetiaan dari satu merek sebuah produk tertentu ke merek produk lainnya. (Manajemen, Made, \& Purnama, 2018) dengan adanya brand image yang melekat diproduk xiomi dan oppo yang membuat produk menjadi mudah diingat menyebabkan perputaran merek dari Xiomi ke Oppo karena brand image adalah kemajuan tekonologi yang sangat pesat terutama smarthphone.

\section{Kerangka berpikir}

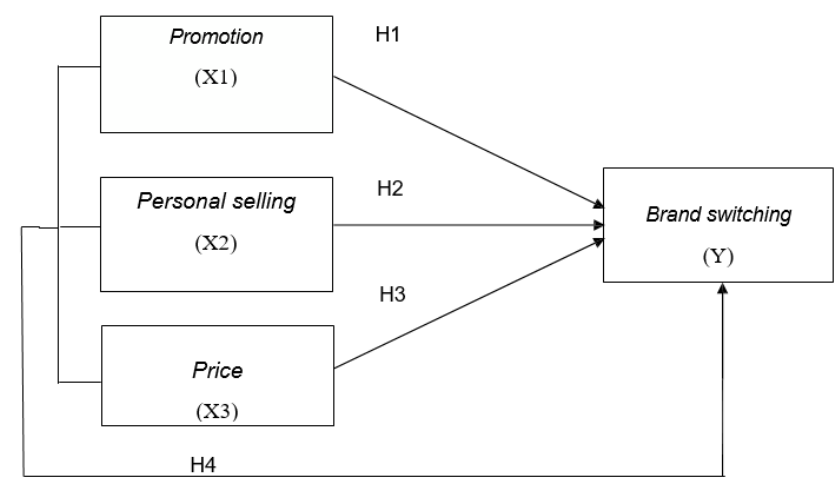

Gambar 1.1

\section{Hipotesis}

H1: Promotion (X1) berpengaruh positif dan signifikan terhadap Brand switching $(Y)$.

H2: Personal Selling (X2) berpengaruh secara positif dan signifikan Terhadap

Brand switching $(\mathrm{Y})$.

H3: Price (X3) berpengaruh positif dan signifikan terhadap Brand Switching (Y).

H4: Promotion (X1), Personal selling (X2), dan price (X3) berpengaruh secara positif dan siginifikan terhadap brand switching $(\mathrm{Y})$.

\section{METODE RISET}

Lokasi penelitian ini berada di (Xiaomi dan Oppo) pada Erafone Megastore di Kota Denpasar. Populasi pada penelitian ini konsumen yang berkunjungpada Erafone Megastore di Kota Denpasar, dengan sampel berjumlah 80 responden melalui penyebarann kuesioner dengan alat ukur skala likert. Teknik penentuan sampel yang 
digunakan pada penelitian yaitu sampling aksidental dengan rumus Hair et al. Jenis data yang digunakan pada penelitian ini yaitu data kuantitatif. Teknik analisis data yang digunakan pada penelitian ini yaitu menggunakan regresi linier berganda, dalam perhitungannya menggunakan software dengan progam SPSS version 22 for Windows.

\section{HASIL DAN PEMBAHASAN}

Data dalam peneltian ini diperoleh dari 80 orang responden melalui penyebaran kuesioner. Pemaparan berikut ini meliputi dua kriteria responden yaitu berdasarkan usia, jenis kelamin, pendidikan, pendapatan dan pekerjaan. Pada penelitian ini berdasarkan usia yaitu responden didominasi oleh usia 15 - 25 tahun yaitu sebanyak 50 orang atau sebesar $62,5 \%$, responden berdasarkan jenis kelamin didominasi perempuan dimana perempuan sebanyak 45 dengan persentase $56,3 \%$, responden pada penelitian ini memiliki sebagian bersar responden belum berpendapatan yaitu sebanyak 41 dengan persentase $51,3 \%$, responden pada penelitian sebagian besar adalah pelajar/masasiswa sebanyak 51 dengan persentase $63,8 \%$.

Berdasarkan hasil uji instrument dengan penyebaran kuesioner pada 80 orang responden, seluruh indikator variable padaa penelitian ini yaitu Promotion, Personal Selling, Price terhadap Brand Switching valid karena memiliki nilaii koefisien korelasii lebih dari 0,30 . Begitu juga dengan hasil uji reliable, instrument dalam penelitian variabel-variabel penelitian dikatakan reliable karenammasing-masing variabel memiliki nilai Alpha lebih besar 0,60. Berdasarkan uji normaliitas, niilai Assymp. Sig. (2-tailed) adalahh sebesar 0,256 yaitu lebih besar dari 0,05 yang menunjukan bahwa data terdistriibusi secara normal. Berdasarkan uji multiikolineritas ditunjukkan bahwa seluruhh variabel bebas memiliki nilai tolerance $>0,10$, begitu juga dengan hasil perhitungan nilai VIF, seluruh variabel memiliki nilai VIF $<10$. Hal iini berariti bahwa paada model regresii yang dibuat tidak terdapat gejala multikolineariitas.

Berdasarkan uji heterokedastisiitas bahwa masing-masing model memiliki nilai signifiikansi lebih besar darii 0,05. Berarti didalam model regresi ini tidak terjadi kesamaan variian dari residuall satu pengamatann ke pengamatan lainnya atau tidak terjadi heteroskedastisitas. Pengujian data pada peneliitian ini menggunakan tekniik regresii liniier berganda diolah dengan software Statistical Package for Social Sciences (SPSS) Promotion, Personal Selling, Price terhadap Brand Switching dapat dianalisis menggunakan perhitungan regresii liniier berganda.

Tabel 1

Hasil Uji Analisis Regresi Linear Berganda Coefficients $^{a}$

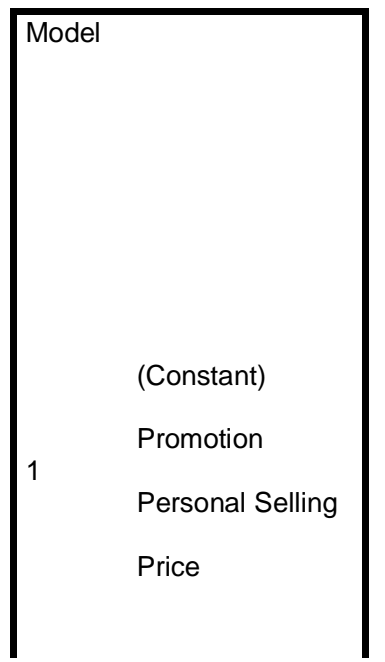

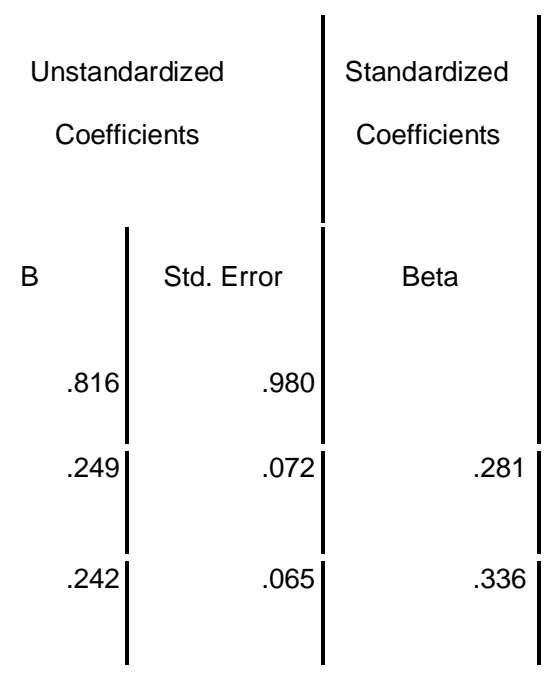

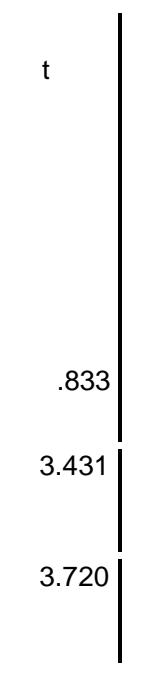

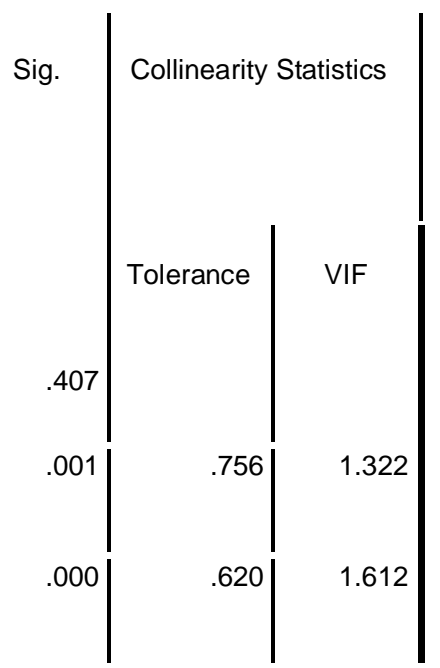




$$
\begin{array}{ll|l|l|l|l|l|l|}
.261 & .058 & .372 & 4.487 & .000 & .738 & 1.356
\end{array}
$$

Sumber : data diolah.

Berdasarkan tabel hasil uji analisis regresi linear berganda tersebut diatas, maka persamaan regresi dalam penelitian ini adalah sebagai berikut :

$\mathrm{Y}=0.816+0.249 \mathrm{X} 1+0.242 \mathrm{X} 2+0.261 \mathrm{X} 3+\mathrm{e}$

Keterangan :

- Koefisien konstanta sebesar 0.816 yang memiliki makna bahwa apabila variabelyaitu promotion, personal selling dan price pada angka nol (0) maka brand switching (Y) sebesar konstan yaitu 0.816 .

- Nilai koefisien regresi social promotion adalah sebesar 0,249 artinya setiap peningkatan pada variabel promotion dapat meningkatkan brand switching. Apabila promotion mengalami peningkatan sebesar 1 satuan maka brand switching akan mengalami peningkatan sebesar 0.249 .

- Nilai koefisien regresi personal selling adalah sebesar 0,242 artinya setiap peningkatan pada variabel personal selling dapat meningkatkan brand switching. Apabila promotion mengalami peningkatan sebesar 1 satuan maka brand switching akan mengalami peningkatan sebesar 0.249 .

- Nilai koefisien regresi price adalah sebesar 0,261 artinya setiap peningkatan pada variabel price dapat meningkatkan brand switching. Apabila price mengalami peningkatan sebesar 1 satuan maka brand switching akan mengalami peningkatan sebesar 0.261.

Tabel 2

Uji Koefisien Determinasi

Model Summary

\begin{tabular}{|c|c|c|c|c|}
\hline Model & $\mathrm{R}$ & R Square & Adjusted R Square & $\begin{array}{l}\text { Std. Error of the } \\
\text { Estimate }\end{array}$ \\
\hline 1 & $.784 a$ & .614 & .599 & 1.321 \\
\hline
\end{tabular}

Sumber : Data diolah

Dari hasil pengujian pada tabel 4.16 menunjukkan besarnya (R2) adalah 0,599, Hal ini berarti 59,9\% variasi variable brand switching dapat dijelaskan oleh variasi dari ketiga variable independent promotion,personal selling dan price. sedangkan sisanya (100\%$59,9 \%=40,1 \%$ ) dijelaskan oleh sebab-sebab lain diluar model yaitu seperti variable brand image, kepercayaan, service quality.

Tabel 3

Nilai Standardized Coefficients Beta Promotion, Personal Selling dan Price

\begin{tabular}{|l|c|c|}
\hline \multicolumn{1}{|c|}{ Variable } & $\begin{array}{c}\text { Standardized } \\
\text { Coefficients Beta }\end{array}$ & Ranking \\
\hline Promotion(X1) & 0,281 & 3 \\
\hline Personal Selling(X2) & 0,336 & $\mathbf{9}$ \\
\hline
\end{tabular}




\begin{tabular}{|l|l|l|}
\hline $\operatorname{Price}(\mathrm{X} 3)$ & 0,372 & 1 \\
\hline
\end{tabular}

Sumber : Data diolah

Berdasarkan hasil perhitungan analisis standardized coefficients beta diketahui variable promotion memiliki nilai koefisien beta sebesar 0,281 , variable personal selling memiliki nilai koefisien beta sebesar 0,336 dan variable price memiliki koefisien beta sebesar 0,372 . Diantara ketiga variable bebas tersebut, variable price memiliki nilai standardized coefficients beta terbesar yaitu sebesar 0,372 sehingga dapat dikatakan bahwa price berpengaruh dominan terhadap brand switching. Hal ini karena harga memiliki peran yang kuat dalam mempengaruhi konsumen. Hal ini karena seseorang sebelum membeli sesuatu cenderung akan memperhitungkan price (harga) terlebih dahulu bagaimana dan berapa harga yang akan dikeluarkan konsumen sehingga konsumen tersebut melakukan transaksi.

\section{Kesimpulan}

\section{SIMPULAN DAN SARAN}

Berdasarkan pembahasan yang telah diuraikan pada bab sebelumnya maka diperoleh simpulan sebagai berikut :

1. Promotion nmemiliki pengaruh yang positif dan signifikan terhadap brand switching. ini berarti bahwa semakin baik promosi yang dilakukan Oppo maka akan meningkatkan keinginan konsumen untuk berpindah dari Xiaomi ke Oppo.

2. Personal selling memiliki pengaruh yang positif dan signifikan terhadap brand switching. ini berarti bahwa semakin baik personal selling yang dilakukan yang dilakukan Oppo maka akan meningkatkan keinginan konsumen untuk berpindah dari Xiaomi ke Oppo.

3. Personal selling memiliki pengaruh yang positif dan signifikan terhadap brand switching. ini berarti bahwa semakin seusai harga produk Oppo dengan kualitas yang ditawarkan maka akan meningkatkan keinginan konsumen untuk berpindah dari Xiaomi ke Oppo.

4. Promotion, personal selling dan price secara bersama-sama memiliki pengaruh yang signifikan terhadap brand switching. ini berarti bahwa semakin baik promotion, personal selling dan price maka akan meningkatkan keinginan konsumen untuk berpindah dari Xiaomi ke Oppo.

5. Dari penelitian pengaruh promotion, personal selling dan price terhadap brand switching. Diketahui pada penelitian ini price dengan nilai kofisien sebesar 0,372 memiliki pengaruh yang paling kuat dibandingkan personal

selling sebesar 0,336 dan promotion sebesar 0,281. Hal ini karena harga memiliki peran yang kuat dalam mempengaruhi konsumen. Hal ini karena

seseorang sebelum membeli sesuatu cenderung akan memperhitungkan price

(harga) terlebih dahulu bagaimana dan berapa harga yang akan dikeluarkan konsumen sehingga konsumen tersebut melakukan transaksi.

\section{Saran}

Promosi lewat media sosial dengan bekerja sama dengan selebgram dan menggungah video dan foto mengenai kelebihan Oppo di akun media sosial Oppo, serta melakukan promosi secara konfensional seperti memasang baliho di setiap toko yang menjual produk Oppo, selain itu Oppo lebih memperluas personal selling dengan langsung kerumah-rumah menawarkan sekaligus menjelasakan kelebih produk Oppo, selain itu dalam memberika harga Oppo hendaknya memberikan harga yang sesuai dengan kualitas yang ditawarkan dan memperhatikan harga dari produk sejenis. Bagi peneliti selanjutnya, agar dapat meneliti dan mengkaji lebih dalam faktor-faktor lain yang tidak diteliti dalam penelitian ini yang dapat mempengaruhi brand switching pada selain promotion, personal selling dan price. Agar nantinya dapat mengetahui tindakan apa yang harus dilakukan untuk meningkatkan brand switching. 


\section{REFERENSI}

Ahmad, Y. (2016). Pengaruh Harga Dan Promosi Terhadap Keputusan Pembelian Laptop Merek Acer. Ekonomi, (024), 4.

Anisa, N. A., \& Harti. (2015). Pengaruh Promosi Dan Kualitas Produk Terhadap Perilaku Beralih Merek (Brand Switching) Ke Kartu Perdana Telkomsel (Studi Pada Mahasiswa Universitas Negeri Surabaya). Jurnal Fakultas Ekonomi. Retrieved from http://e-journal.

Candra, J. (2014). Pengaruh Faktor Promosi, Kualitas Produk, Dan Ketidakpuasan

Terhadap Perpindahan Merek. Ilmu Manajemen, 2.

Cendriyansyah, Y., \& Mustikasari, A. (2017). Problem Recognitionselling Terhad Pengaruh personal ap Keputusan Pembelian ( Studi kasus pada PerumPerumnas perumhan Bumi Parahiyangan Kencana Soreang Bandung) Inform Search. E-Proceeding of Applied Science, 3(2), 1-10.

Harga, P., Dan, P., Layanan, K., Card, S. I. M., Di, G. S. M., \& Sekaran, K. (2011).

Terhadap brand switching pada pelanggan kecamatan gunungpati semarang.

Haji, A. (2014). Pengaruh Atribut Produk, Promosi, Harga, Dan Customer Trust Terhadap Brand Switching Konsumen Produk Kartu Perdana Axis (Studi Kasus Pada Mahasiswa Fakultas Ekonomi Universitas Maritim Raja Ali Haji).

$1-14$.

Kasus, S., \& Depok, K. (2018). Pengaruh ketidakpuasan konsumen, mencari variasi, harga, dan promosi terhadap perpindahan merek asus zenfone ke merek lain.

Kotler. (2016). Pengaruh Personal Selling Terhadap Keputusan Pembelian. E- Proceeding of Applied Science, (X).

Kusuma, B. A. (2015). Analisis faktor-faktor yang mempengaruhi keputusan pembelian konsumen ponsel merek samsung. 7(3).

Manajemen, J. I., Made, D., \& Purnama, F. (2018). Brand Image Dan Brand

Awareness Terhadap Customer Loyalty. 3(1), 14-24.

Prasetyo, A. A., \& Ridwanudin, O. (2017). Pengaruh Personal Selling Terhadap Keputusan Berkunjung Di Jendela Alam. THE Journal : Tourism and HospitalityEssentialsJournal,6(2),1077.https://doi.org/10.17509/thej.v6i2.558 
Rizan, M., \& Anjasrestu, Y. (2013). Pengaruh Kualitas Produk Dan Personal Selling Terhadap Kepuasan Pelanggan Pada Majalah Info Bekasi ( Studi Kasus Pt . Sibk ). Jurnal Riset Manajemen Sains Indonesi, 4(1), 74-96.

Terhadap, P., Merek, P., Kartu, S., Di, S., Totalwin, S., \& Jatmiko, M. R. (2013).

Analisis Pengaruh Promosi, Harga, Dan Atribut Produk Terhadap Perpindahan Merek (Brand Switching) Kartu Seluler Di Stie Totalwin Semarang. Jurnal Sains Pemasaran Indonesia, 12(2), 157-167.

Syachran, F. (2018). Pengaruh iklan dan personal selling terhadap brand image indosat di kota makassar ( studi pada pengguna kartu indosat di kota makassar ).

Uswatun, A., \& Kuswati, R. (2014). Analisis faktor-faktor yang mempengaruhi ( Studi Kasus pada Mahasiswa Universitas Muhammadiyah Surakarta yang Melakukan Perpindahan Merek dari Blackberry ke non Blackberry ). Aulia Uswatun Khasanah1 Dan Rini Kuswati2 Universitas, (Sancall), 5-11.

Wibowo, S. F., Kurnaen, T., \& P, A. K. R. (2014). Pengaruh atribut produk dan variety seeking terhadap keputusan perpindahan merek handphone nokia ke smartphone samsung ( Survei pada outlet Okeshop ITC Roxy Mas , Jakarta Pusat ). Jurnal Riset Manajemen Sains Indonesia, 5(1), 21-41. 